\title{
A Systematic Review of Thulium Fiber Laser: Applications and Advantages of Laser Technology in the Field of Urology
}

\author{
Patrick Rice' \\ Bhaskar K Somani (iD) ${ }^{1,2}$ \\ 'Department of Urology, University \\ Hospital Southampton NHS Trust, \\ Southampton, UK; ${ }^{2}$ Manipal Academy of \\ Higher Education, Manipal, India
}

\begin{abstract}
Laser technology is widely used in urological surgery, from lithotripsy, prostate surgery to en-bloc resection of tumours. While Holmium:YAG has been widely employed over the last two decades, in recent years, there has been a surge of interest in Thulium Fiber Laser (TFL), which offers theoretical advantages of better water absorption and lower stone ablation thresholds. A systematic review was conducted to assess the evidence from clinical research on TFL's application for lithotripsy and prostate surgery. It identified 357 articles and 8 (1506 patients) were selected, of which 4 clinical studies each investigated TFL enucleation of prostate (ThuFLEP) and TFL lithotripsy. For flexible ureteroscopic lithotripsy (FURSL), stone ablation settings ranged from $0.1-4 \mathrm{~J}$, and 7-300 Hz, mean operative time ranged from 23.4-39.8 minutes and lasing time ranged from 1.2-10 minutes. For stone dusting in percutaneous nephrolithotomy (PCNL), settings of $0.2 \mathrm{~J}$ and $125-200 \mathrm{~Hz}$ were found to be optimal. For ThuFLEP, all studies showed a significant improvement in IPSS (International Prostate Symptom Score), urinary flow rate $\left(\mathrm{Q}_{\max }\right)$, quality of life measures, and post-void residual volume, with mean operative time ranging from 67-104.5 minutes. Our review shows that there is limited evidence on the use and clinical outcomes of TFL. ThuFLEP might suggest equivalence to the widely used HoLEP in the available evidence so far. TFL lithotripsy shows promising results but further prospective, randomized trials are required to properly assess its usability, clinical effectiveness and standardisation of the settings for successful adoption of the technology.
\end{abstract}

Keywords: ureteroscopy, percutaneous nephrolithotomy, kidney calculi, BPH, TFL, thulium fiber laser

\section{Introduction}

Minimally invasive surgery (MIS) has seen large uptake in recent decades, with increasing numbers of such procedures being performed. ${ }^{1}$ Laser technology is widely used in the management of urological diseases, including urolithiasis, benign prostatic enlargement (BPE), and urinary tract malignancies. ${ }^{2}$ Laser lithotripsy was first adopted by urologists in the 1980s, ${ }^{3,4}$ with Holmium:YttriumAluminium-Garnet (Ho:YAG) becoming the laser of choice in the mid 1990s. ${ }^{5,6}$ In recent years, there has been a surge of interest in Thulium Fiber Laser (TFL) which has a $4 \mathrm{x}$ higher absorption coefficient in water-containing tissue, smaller operating fibers $(50-150 \mu \mathrm{m}$ core diameter), lower energy pulses $(0.025 \mathrm{~J})$, and higher pulse rate capability (up to $2 \mathrm{KHz}$ ). The theoretical benefits of TFL have seen its application outside of stone surgery, in soft tissue surgery such as BPE and
Correspondence: Bhaskar K Somani University Hospital Southampton NHS

Trust, Southampton, UK

Tel +44238I206873

Email bhaskarsomani@yahoo.com 
bladder tumour en-bloc resection., ${ }^{7,8}$ TFL has demonstrated efficacy and safety in ex vivo research and is now being deployed in clinical research. ${ }^{9,10}$

One advantage of TFL is its higher water-absorption coefficient compared with Ho:YAG, which means that water absorbs TFL energy around four times higher than it does with Ho:YAG laser energy. Using water absorption as a model for cell absorption, the implication of this is that more energy from TFL is absorbed by cells and therefore they are better ablated. A further implication is that this leads to lower vapor-channel-initiation thresholds, ${ }^{11,12}$ leading to the "Moses" effect detailed below. A further advantage is the lower ablation thresholds for many different urinary stone compositions compared with Ho: YAG. For example, hard stone compositions such as calcium oxalate monohydrate and soft stone compositions such as uric acid have much lower stone ablation thresholds, and are therefore easier to ablate than with Ho: YAG. ${ }^{11,13-15}$ This allows either lower settings with equal stone ablation results to Ho:YAG, or higher stone ablation volume at the same settings.

The ability to produce equal stone ablation at lower energy settings leads to two pragmatic benefits of TFL. Firstly, the lower energy settings lead TFL to being less prone to stone retropulsion. Stone retropulsion describes the effect where calculi are being pushed away, in addition to being ablated, by high-energy laser bursts. As described in an in vitro study with the conventional Ho:YAG laser, retropulsion increases linearly with pulse energy. ${ }^{14}$ This is a troublesome effect for the endoscopist, leading the need to "chase" stones or for the stones to go proximally in the kidney. In addition to this, fewer small fragments are propelled into view of the endoscope, reducing the storm of fragments often seen through the endoscope, improving the endoscopic view during lithotripsy. ${ }^{16}$

The "Moses effect" was first described in 1986 and describes delivering short, low energy pulses to create a bubble through which to deliver the ablative burst. ${ }^{17}$ While travelling through the parted water, the laser is not absorbed, therefore increasing the intensity of energy delivered to a calculus. This "Moses" effect is also reported by the uniform pulse energies of TFL, and due to the lower power, uniformity, and lack of a peak, there is local pressure an order of magnitude lower than Ho: YAG. ${ }^{16-21}$

\section{Materials and Methods}

\section{Evidence Acquisition}

Inclusion Criteria

1. Study the use of Thulium Fiber Laser.

2. Clinical research.

3. English language articles.

\section{Exclusion Criteria}

1. Animal or laboratory studies or non-clinical research.

2. Case reports, review articles, conference abstracts.

3. Investigated non-urinary tract applications.

\section{Search Strategy and Study Selection}

The systematic review was performed in accordance with the Cochrane Handbook and the Preferred Reporting Items for Systematic Reviews and Meta-Analyses (PRISMA). ${ }^{19,20}$ Figure 1 details the search strategy and the PRISMA flowchart. Searches were performed for results between the inception of the databases and January 2021. "MeSH" or database-equivalent terms included "Prostatic hyperplasia", "Lithotripsy", "stone" and "Urolithiasis". Specific search terms included "thulium", "fiber", "laser", "BPH", and "TFL". These databases included: MEDLINE, EMBASE, Scopus, CINAHL and Cochrane Library. A manual search of "grey literature" was also performed.

\section{Results}

The initial set of 357 articles were identified through searches of various databases. After removal of duplicates, 294 articles were screened of which 246 abstracts were further evaluated. Sixty full text articles were obtained and finally eight studies (1506 patients) were selected for our review. These studies were published between 2018-2021. The PRISMA diagram is displayed in Figure 1.

There were four studies published on lithotripsy (two on Percutaneous Nephrolithotomy [PCNL] and two on Flexible Ureteroscopy with Lithotripsy [FURSL]) and four studied the use of Thulium Laser Enucleation of Prostate (ThuFLEP).

\section{Stone Surgery}

Results of stone surgery studies are presented in Table 1. Laser settings ranged from $0.1-4 \mathrm{~J}$, and 7-300 Hz. One study that specifically investigated optimal settings for stone dusting in PCNL found $0.2 \mathrm{~J}$ and $125-200 \mathrm{~Hz}$ to 


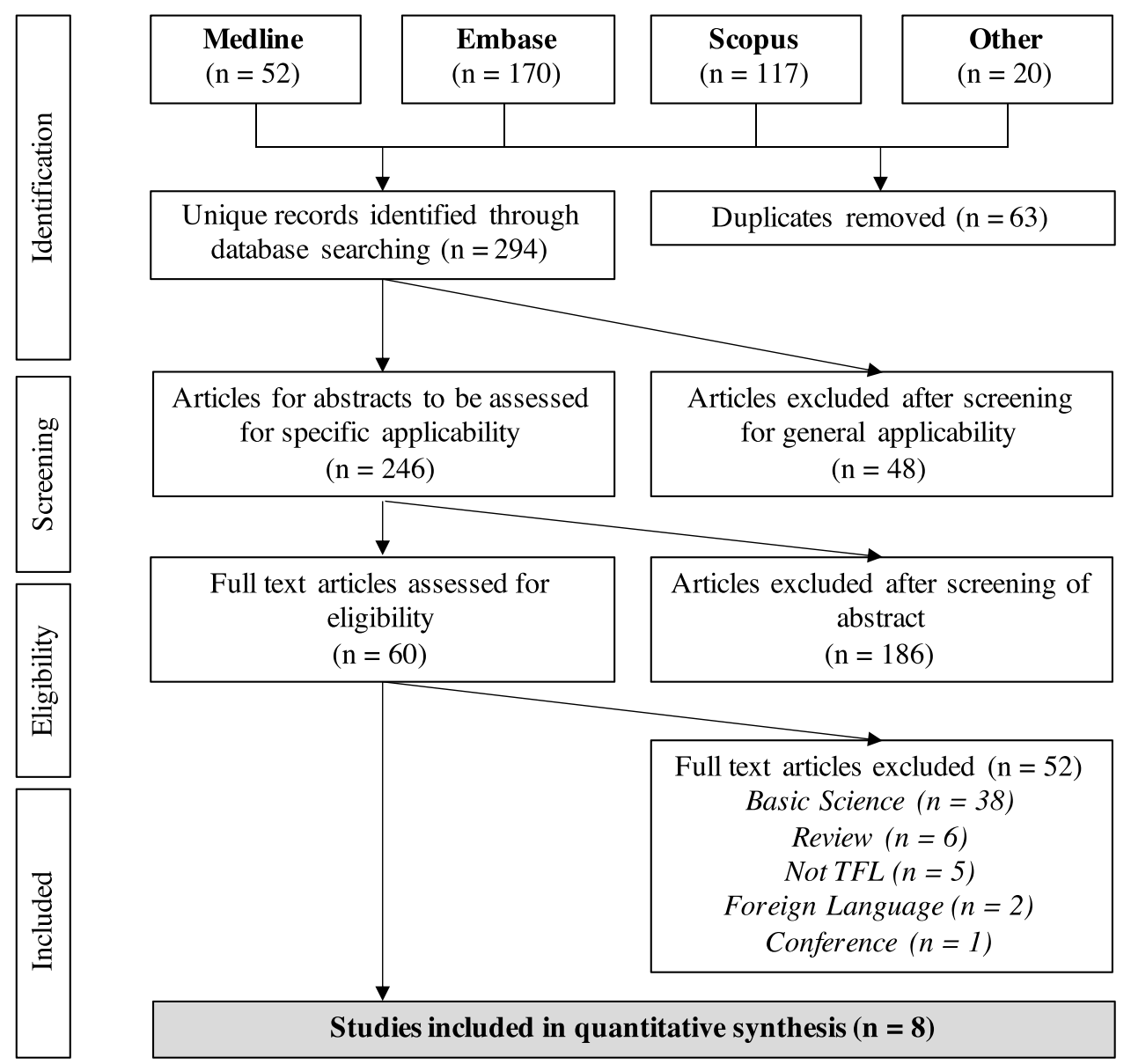

Figure I PRISMA flowchart of the included studies.

Note: Adapted from Moher D, Liberati A, Tetzlaff J, et al. Preferred reporting items for systematic reviews and meta-analyses: the PRISMA statement. PLoS Med. 2009;6(7): el000097. Creative Commons licence and disclaimer available from: http://creativecommons.org/licenses/by/4.0/legalcode. ${ }^{20}$

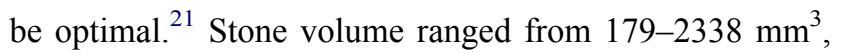
stone density ranged from 880-1301 Hounsfield Units (HU), mean operative time (MOT) ranged from 23.4 39.8 minutes. Laser on time (LOT) ranged from 1.2 to 10 minutes. Other outcomes and complications are reported in Table 1.

\section{Prostate Laser Enucleation}

Results of prostate laser enucleation studies are presented in Table 2. One study used the FiberLase U1, and three studies used the Urolase TFL. Mean Prostate Specific Antigen (PSA) ranged from 4.5-5.2. Mean prostatic volume ranged from $59.5-127.8 \mathrm{~cm}^{3}$. Mean operative time ranged from 67-104.5 minutes. All studies showed a significant improvement in IPSS (International Prostate Symptom Score), urinary flow rate $\left(Q_{\max }\right)$, quality of life measures, and post-void residual volume. In a randomized study, Enikeev et al. found ThuFLEP to have a significantly easier learning curve than HoLEP and monopolar enucleation of prostate (MEP). ${ }^{22}$ In a retrospective study, Enikeev et al. found ThuFLEP to significantly improve erectile function. ${ }^{23}$

\section{Discussion}

\section{Stone Surgery}

Enikeev et al. investigated the clinical efficacy and safety of TFL as a lithotripter during percutaneous nephrolithotomy (PCNL). ${ }^{24}$ The authors observed no correlation between stone density and LOT or operative time, suggesting that density does not affect the ablation efficiency of TFL. With reference to the theoretical advantages of minimal retropulsion and enhanced visibility of TFL: retropulsion that interfered with operative progress was reported in $1.4 \%$ of cases and insignificant retropulsion was reported in $11.7 \%$ of cases; and suboptimal visibility was reported in $14.6 \%$ of cases, with no significant correlation between frequency and visibility noted. Addressing the safety of TFL, the authors suggested that the high- 


\begin{tabular}{|c|c|c|c|c|c|}
\hline \multicolumn{2}{|c|}{ 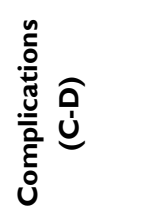 } & 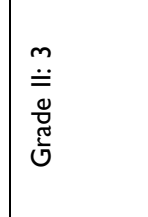 & 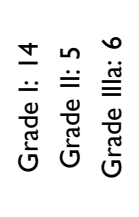 & 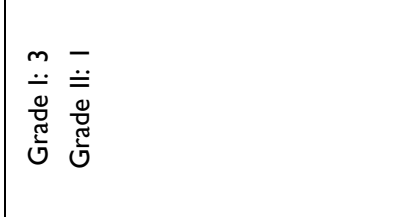 & 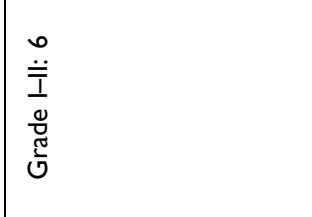 \\
\hline & 离 & 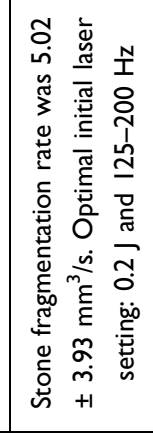 & 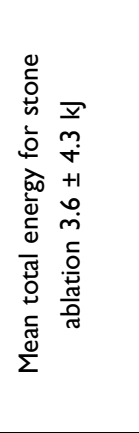 & 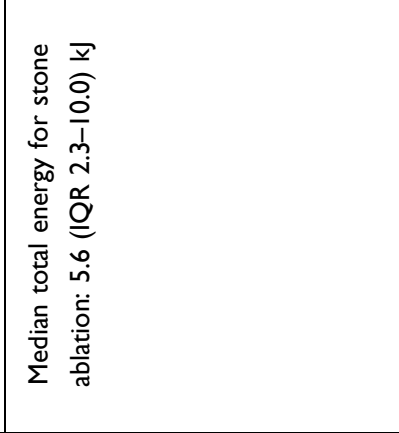 & 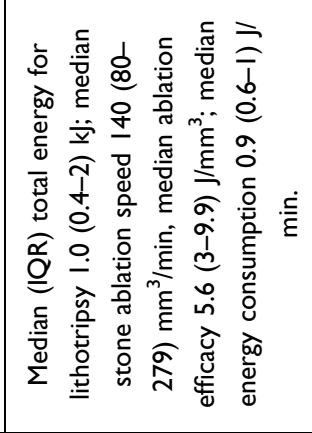 \\
\hline 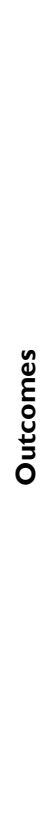 & 呒 & \begin{tabular}{|l}
$\bar{f}$ \\
$i$ \\
+1 \\
0 \\
0 \\
0 \\
0
\end{tabular} & $\begin{array}{l}\hat{n} \\
+1 \\
0 \\
i \\
i\end{array}$ & 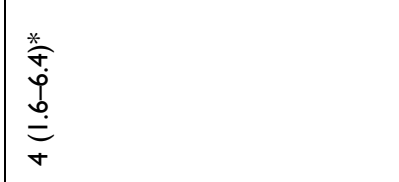 & 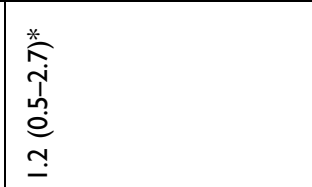 \\
\hline & 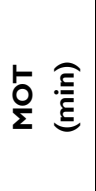 & 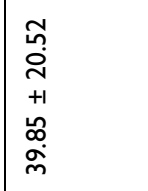 & 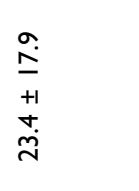 & 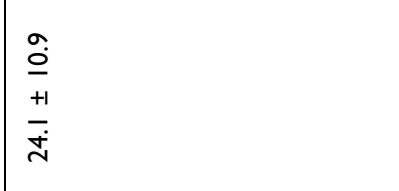 & $\stackrel{\circ}{\mathrm{V}}$ \\
\hline \multirow{2}{*}{ 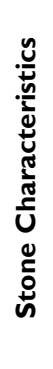 } & 展 & 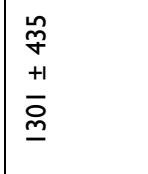 & $\begin{array}{l}\frac{n}{n} \\
+1 \\
+1 \\
o \\
\underline{0}\end{array}$ & $\begin{array}{l}\bar{\infty} \\
0 \\
+1 \\
\infty \\
\infty \\
\infty\end{array}$ & 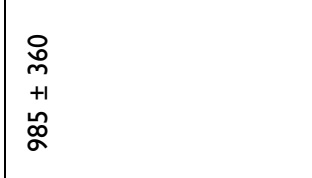 \\
\hline & 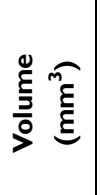 & \begin{tabular}{|l} 
合 \\
$\sigma$ \\
+1 \\
$\infty$ \\
$\tilde{N}$ \\
$\tilde{\gamma}$
\end{tabular} & $\frac{\alpha}{z}$ & 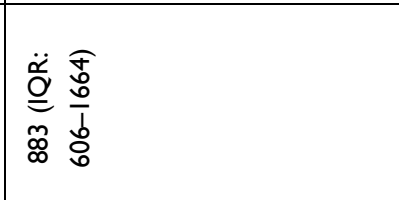 & 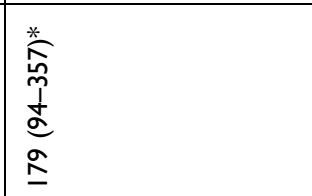 \\
\hline \multicolumn{2}{|l|}{ D. } & 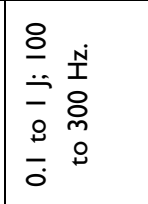 & 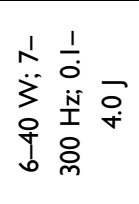 & 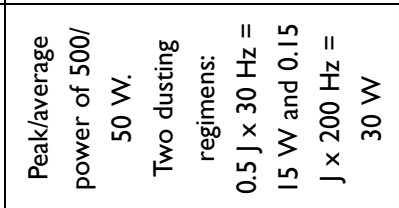 & $\frac{\alpha}{z}$ \\
\hline \multicolumn{2}{|l|}{$z$} & 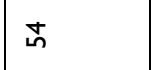 & $\stackrel{\Omega}{\simeq}$ & q & $\underset{q}{q}$ \\
\hline \multicolumn{2}{|c|}{ 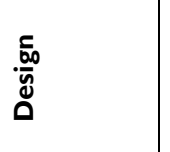 } & 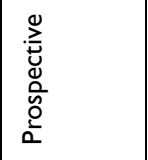 & 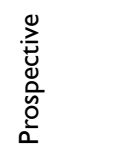 & 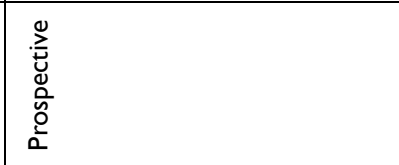 & 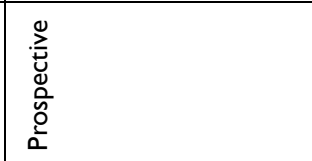 \\
\hline \multicolumn{2}{|c|}{ 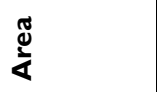 } & 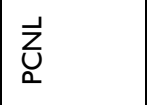 & $\underset{\substack{u \\
\alpha}}{\vec{z}}$ & \begin{tabular}{|l}
$\overrightarrow{\hat{\sigma}}$ \\
$\overrightarrow{\underline{\mu}}$
\end{tabular} & \begin{tabular}{|l}
$\overrightarrow{\hat{\sigma}}$ \\
$\frac{\tilde{\rho}}{\vec{\nu}}$
\end{tabular} \\
\hline \multicolumn{2}{|c|}{ 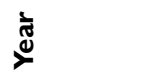 } & ڤ̊ & సి & స్ & ๙ิి \\
\hline \multicolumn{2}{|c|}{$\stackrel{0}{\circ}$} & 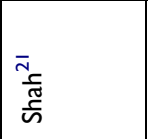 & 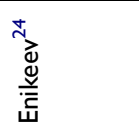 & 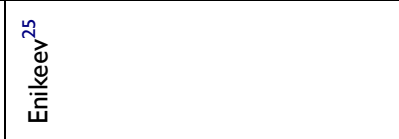 & 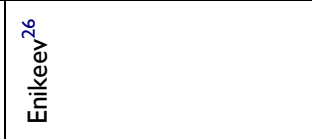 \\
\hline
\end{tabular}




\begin{tabular}{|c|c|c|c|c|}
\hline 递 & 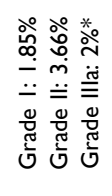 & 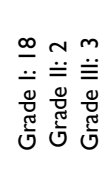 & $\begin{array}{l}\frac{*}{*} \\
\frac{\alpha}{z}\end{array}$ & 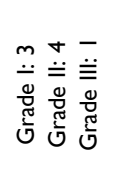 \\
\hline 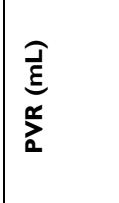 & 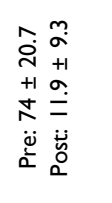 & 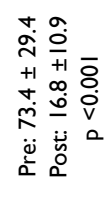 & 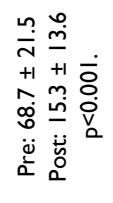 & 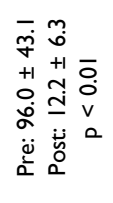 \\
\hline 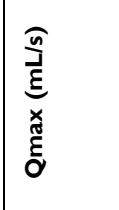 & 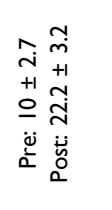 & 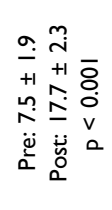 & 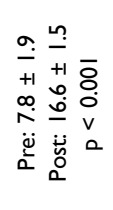 & 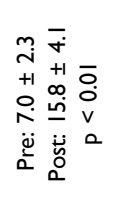 \\
\hline$\stackrel{1}{\circ}$ & 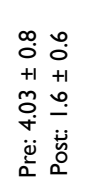 & 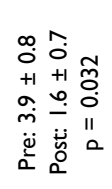 & 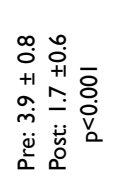 & 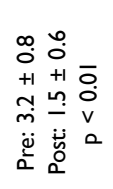 \\
\hline 岕 & 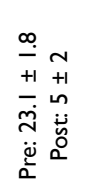 & 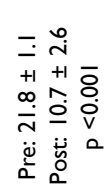 & 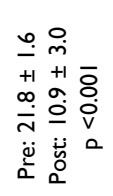 & 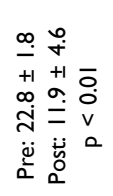 \\
\hline 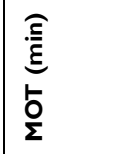 & $\begin{array}{l}0 \\
+1 \\
+1\end{array}$ & $\begin{array}{l}\stackrel{0}{0} \\
\stackrel{\infty}{0} \\
+1 \\
\stackrel{0}{0} \\
\stackrel{0}{0}\end{array}$ & $\approx$ & $\begin{array}{l}\stackrel{0}{0} \\
m \\
+1 \\
0 \\
\stackrel{0}{0} \\
\underline{0}\end{array}$ \\
\hline 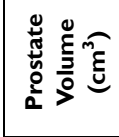 & $\begin{array}{l}q \\
+1 \\
\infty \\
\infty\end{array}$ & $\begin{array}{l}+1 \\
\stackrel{+}{\infty} \\
\stackrel{\mathfrak{I}}{\leftrightarrows}\end{array}$ & 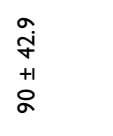 & 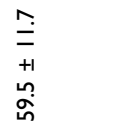 \\
\hline ธ్ & \begin{tabular}{l}
$n$ \\
+1 \\
\multirow{n}{n}{} \\
$n$
\end{tabular} & 兑 & $\begin{array}{l}\hat{i} \\
+1 \\
\hat{+}\end{array}$ & $\begin{array}{l}\stackrel{\infty}{i} \\
+1 \\
+1 \\
\sim\end{array}$ \\
\hline$z$ & $\frac{\mathfrak{N}}{\infty}$ & \& & $\overline{\bar{N}}$ & 이 \\
\hline 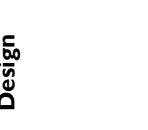 & 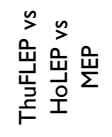 & 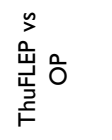 & 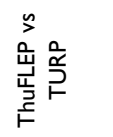 & 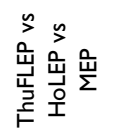 \\
\hline & 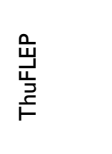 & 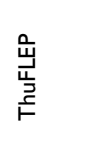 & 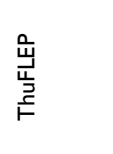 & 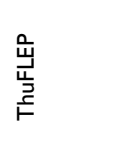 \\
\hline ઇ & 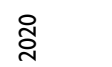 & $\frac{\sigma}{\bar{\alpha}}$ & $\frac{\infty}{a}$ & $\frac{\infty}{i}$ \\
\hline خذئ & 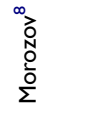 & 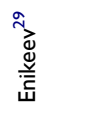 & 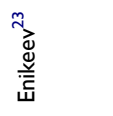 & 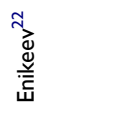 \\
\hline
\end{tabular}


powered lasers $(25-40 \mathrm{~W})$ used for lithotripsy should have no detrimental effect on urinary tissue, with the authors finding no cases of strictures or stenosis at 3 month followup.

Shah et al. investigated the use of TFL in minipercutaneous nephrolithotomy (PCNL) with suction in a prospective study. ${ }^{21}$ The authors sorted through stone sizes using sieves to calibrate the TFL settings to perform mainly dusting and therefore allowing the use of concurrent dust aspiration to decrease operative time. They achieved a $100 \%$ stone-free rate at one month, with a mean operative time of 39.9 minutes. Their optimal settings varied with stone density (in Hounsfield Units) ranging from frequencies of $125-200 \mathrm{~Hz}$ and a consistent energy of $0.2 \mathrm{~J}$.

Regarding Flexible Ureterorenoscopy with Lithotripsy (FURSL), Enikeev et al. prospectively studied the use of SuperPulsed TFL for 10-30 $\mathrm{mm}$ renal calculi, focussing on comparing two regimens for dusting: $0.5 \mathrm{~J}$ x $30 \mathrm{~Hz}=$ $15 \mathrm{~W}$ and $0.15 \mathrm{~J} \times 200 \mathrm{~Hz}=30 \mathrm{~W}^{25}$ They found that both ablation efficiency and speed were higher in $200 \mathrm{~Hz}$ mode without the drawbacks of increased laser-on time nor increased intraoperative complication rates. Visibility was comparable between groups, with only $2.5 \%$ of cases in the $30 \mathrm{~Hz}$ group and $5 \%$ of cases in the $200 \mathrm{~Hz}$ group having an impairment in visibility.

In a further study, Enikeev et al. analysed the efficacy and safety of SuperPulsed TFL lithotripsy, using a wide variety of pulse frequencies and powers. ${ }^{26}$ The study found retropulsion to have positive correlation with pulse energy and that decreased visibility was associated only with high retropulsion. There were no reliably predictive indicators of poor visibility identified. The authors concluded that the optimal settings for stone fragmentation were: $0.5 \mathrm{~J}$ x $30 \mathrm{~Hz}$ and for dusting were: $0.15 \mathrm{~J}$ x $100 \mathrm{~Hz}$. Their overall stone-free rate at 3 months was $90 \%$.

\section{Prostate Laser Enucleation}

An additional application of TFL is in prostatic enucleation, as demonstrated in Thulium Fiber Laser Enucleation of Prostate (ThuFLEP). As with lithotripsy, Ho:YAG has been the mainstay for endoscopic laser enucleation of prostate (HoLEP) with recurrence rates of less than $5 \%{ }^{27}$ However, HoLEP is considered technically challenging with a steep learning curve. ${ }^{28}$ In a randomized study, ThuFLEP was compared with HoLEP and MEP. ${ }^{22}$ The authors found that ThuFLEP was associated with simple learning curve, achieving proficiency in as few as $8-16$ procedures. This illustrates a key advantage over HoLEP which typically requires $50-60$ procedures ${ }^{27}$ However, the authors found no significant difference in enucleation rates between ThuFLEP and HoLEP. A popular setting for prostate enucleation is $0.5-1 \mathrm{~J} \times 30-80 \mathrm{~Hz}$.

Enikeev et al retrospectively compared ThuFLEP with Open simple Prostatectomy (OP) for large volume prostate, focussing on comparing lower urinary tract symptoms, quality of life, maximum urine flow rate, and postvoid residual urine volumes. ${ }^{29}$ The two procedures had comparable operative times and resection speed. ThuFLEP was associated with a shorter hospital stay and catheterisation time when compared to OP. Furthermore, ThuFLEP demonstrated significant improvements in LUTS as measured by International Prostate Symptom Score (IPSS), quality of life, and maximum urine flow rate.

A further study compared ThuFLEP with Transurethral Resection of Prostate (TURP) for BPH, with both modalities being equally effective at resolving LUTS at 6 months postoperatively. $^{23}$ Interestingly, patients receiving ThuFLEP had a significant improvement in erectile function on average postoperatively. The authors suggest that this is due to TFL's shallower penetration depth, allowing safer incisions with a lower risk of surgical capsule penetration and therefore less damaging on neurovascular bundles at the posterolateral surface of the prostate.

\section{Other Applications Upper Tract Urothelial Carcinoma (UTUC)}

Due to the biologically aggressive nature of Upper-Tract Urinary Carcinomas (UTUC), ${ }^{30}$ radical nephroureterectomy with excision of the bladder cuff (RNU) has been considered the "gold standard" management. The use of risk-stratification approaches to accurately identify patients with low-risk UTUC has allowed the development of kidney-sparing, endoscopic approaches. ${ }^{31,32}$ In a retrospective series of 129 patients over 20 years comparing endoscopic versus laparoscopic management of UTUC, the endoscopic group showed high renal preservation $(82.5 \%)$ at the cost of high local recurrence in five years $(49.3 \%$ versus $100 \%)$ for all tumour grades. ${ }^{33}$ However, when broken down by grade, five-year progression-free survival of $100 \%, 89.4 \%$ and $88.9 \%$ for the laparoscopic group compared with $96.0 \%, 58.6 \%$ and $55.6 \%$ for the endoscopic group highlights the importance of restricting the endoscopic approach for low-grade tumours. In a retrospective study of Ho:YAG laser-based endoscopic photoablation of UTUC, Villa et al. found 
a progression-free survival rate of $75 \%$ vs $52 \%$ in patients with low vs high grade tumours, with tumour size $>1 \mathrm{~cm}$ and multifocality not increasing the risk of disease progression. ${ }^{34}$ Using Thulium laser as opposed to TFL, for low grade UTUC, Musi et al. found an estimated medial recurrence-free survival of 44 months, with $9.5 \%$ progressing to nephroureterectomy. ${ }^{35}$ In a further study, Wen et al. compared endoscopic management with nephroureterectomy, finding thulium laser treatment to be associated with a lower loss of renal function and a shorter length of stay, but a higher rate of tumour recurrence. ${ }^{36}$ Despite the promising results for other soft-tissue tumours, endoscopic use of TFL remains unreported for UTUC, although it is likely to be used in the future.

\section{Bladder Tumours}

A transurethral approach can be used to manage nonmuscle invasive bladder cancer (NMIBC). Conventional transurethral resection of bladder tumour (cTURBT) utilises a piecemeal incisional approach, which confers risks of thermal damage to nearby tissue as well as fragmentation and seeding of the tumour. The risks of local and bloodstream recurrence were quantified by a recent metaanalysis, highlighting a residual tumour prevalence of 48 $63 \%{ }^{37}$ En-bloc resection of the bladder tumour (ERBT) has seen increased uptake since the late $1990 \mathrm{~s},{ }^{38}$ enabled by developments in laser technology. ERBT aims to resect the entire tumour with a $1 \mathrm{~cm}$ margin, thus better complying with oncological principles. A recent randomised controlled trial compared cTURBT (using monopolar electrocautery) with Holmium laser ERBT (HolERBT), demonstrating promising results for the laser-based approach. ${ }^{39}$ HolERBT conferred a lower residual tumour rate ( $7 \%$ vs $27.7 \%)$, improved detrusor muscle sampling $(98 \%$ vs $62 \%)$, as well as shorter catheterisation time and hospital stay.

TFL offers several theoretical advantages over Holmium, such as the aforementioned decreased penetration depth and the decreased carbonisation (as a result of better water absorption). Presently, the only results of TFL ERBT are in conference presentations, which demonstrated that TFL was feasible ${ }^{7}$ with no post-operative complications exceeding Clavien-Dindo grade I and a relapse rate of $11.6 \%$ at 12 months. At the time of writing, there is a published paper by Enikeev and colleagues who look at the safety and short-term oncological outcomes of TFL for EBRT. ${ }^{40}$

\section{Role of TFL and Areas of Future Research}

There are multiple reasons for TFL having a high efficiency for lithotripsy, including higher water-containing tissue ablation, more effective pulse delivery, and less stone retropulsion. ${ }^{41}$ The higher water-containing tissue ablation lends itself to vaporising water trapped between stone micro-crystals, within stone cracks, and within crevices on the surface of calculi. When these are vaporised, the mechanical force generated by rapidly increasing pressure leads to further stone ablation. ${ }^{11,13,15,42}$ This is an effect which may not be demonstrated by Ho:YAG lasers. ${ }^{43}$ The second contributing factor is found in the pulse settings possible with TFL. A consistent and constant peak power level over time is found with TFL in contrast to the power spikes generated by Ho:YAG. ${ }^{15,44}$ Lastly, the lower stone retropulsion is a contributing factor towards higher lithotripsy efficiency along with the formation of "fine dust" with its use.

While the early TFL results in endourological applications are encouraging, more studies are needed to compare its clinical and safety-related outcomes. Though TFL for stone and BPH use the same system, they have different pulse shape and peak power. Further work on this area is likely to refine and improve the applicability of this technique. As laser machine and fibers can add to the overall cost, this will also need to be taken into account. Apart from comparing the cost of other treatments, patientrelated quality of life also needs to be looked at. ${ }^{45-48}$ Similarly, comparative studies need to look at the outcomes of TFL with other minimally invasive surgical techniques (MIST) such as prostate artery embolization (PAE) and HOLEP for treatment of $\mathrm{BPH}^{49,50}$ In future, there is also a need for more randomised trials and highquality research using TFL to garner more evidence on its use and applicability.

\section{Conclusion}

There is limited evidence on the use and clinical outcomes of TFL. It shows promising results for lithotripsy and prostate treatment, with studies focussed on determining the most appropriate settings and providing initial safety data. Further prospective, randomized research will be needed to assess superiority or non-inferiority to current lithotripsy laser technology and on other applications of TFL, such as in UTUC and en-bloc resection of bladder tumours. 


\section{Disclosure}

The authors report no conflicts of interest in this work.

\section{References}

1. Chughtai B, Scherr D, Del Pizzo J, et al. National trends and cost of minimally invasive surgery in urology. Urol Pract. 2015;2(2):49-54. doi:10.1016/j.urpr.2014.09.002

2. Herrmann TRW, Liatsikos EN, Nagele U, et al. EAU guidelines on laser technologies. Eur Urol. 2012;61(4):783-795. doi:10.1016/j. eururo.2012.01.010

3. Hofstetter A. Laser-science fiction or a new dimension in medicine? Urologe A. 1985;24(6):310-312.

4. Schmidt-Kloiber H, Reichel E, Schöffmann H. Laserinduced ShockWave Lithotripsy (LISL)-Die Laserinduzierte Stoßwellenlithotripsie (LISL); 1985.

5. Hofmann R, Hartung R. Use of pulsed Nd: YAG laser in the ureter. Urol Clin North Am. 1988;15(3):369-375. doi:10.1016/S00940143(21)01578-0

6. Adkins WC, Dulabon DA, Chorazy ZJ, et al. Consider Ho: YAG for low-cost, effective laser lithotripsy. Clin Laser Mon. 1994;12 (9):139-141.

7. Glybochko P, Alyaev Y, Rapoport L, et al. PDD-guided thulium fiber laser en-bloc enucleation of bladder tumor. Eur Urol Suppl. 2018;17 (2):e1967. doi:10.1016/S1569-9056(18)32370-4

8. Morozov A, Taratkin M, Kozlov V, et al. Retrospective assessment of endoscopic enucleation of prostate complications: a single-center experience of more than 1400 patients. $J$ Endourol. 2020;34 (2):192-197. doi:10.1089/end.2019.0630

9. Schembri M, Sahu J, Aboumarzouk O, et al. Thulium fiber laser: the new kid on the block. Turkish J Urol. 2020;46(Supp1):S1-S10. doi:10.5152/tud.2020.20093

10. Kronenberg P, Hameed BMZ, Somani B. Outcomes of thulium fibre laser for treatment of urinary tract stones: results of a systematic review. Curr Opin Urol. 2021;31(2):80. doi:10.1097/ MOU.0000000000000853

11. Fried NM. Recent advances in infrared laser lithotripsy. Biomed Opt Express. 2018;9(9):4552-4568. doi:10.1364/BOE.9.004552

12. Schomacker KT, Domankevitz Y, Flotte TJ, et al. Co: mgF2 laser ablation of tissue: effect of wavelength on ablation threshold and thermal damage. Lasers Surg Med. 1991;11(2):141-151. doi:10.1002/ 1sm.1900110208

13. Fried NM, Irby PB. Advances in laser technology and fibre-optic delivery systems in lithotripsy. Nat Rev Urol. 2018;15(9):563-573. doi:10.1038/s41585-018-0035-8

14. Blackmon RL, Irby PB, Fried NM. Comparison of holmium:YAG and thulium fiber laser lithotripsy: ablation thresholds, ablation rates, and retropulsion effects. $J$ Biomed Opt. 2011;16(7):71403. doi:10.1117/1.3564884

15. Hardy LA, Vinnichenko V, Fried NM. High power holmium:YAG versus thulium fiber laser treatment of kidney stones in dusting mode: ablation rate and fragment size studies. Lasers Surg Med. 2019;51 (6):522-530. doi:10.1002/1sm.23057

16. Ergakov D, Martov AG, Guseynov M. The comparative clinical study of Ho: YAG and superpulse Tm fiber laser lithotripters. Eur Urol Suppl. 2018;17(2):e1391. doi:10.1016/S1569-9056(18)31816-5

17. Isner JM, Clarke RH, Katzir A, et al. transmission characteristics of individual wavelengths in blood do not predict ability to accomplish laser ablation in a blood field-inferential evidence for the moses effect. Circulation. 1986;74:361.

18. Glybochko P, Altshuler G, Vinarov A, et al. Comparison between the possibilities of holmium and thulium laser in lithotripsy in vitro. Eur Urol Suppl. 2017;3(16):e391-e392. doi:10.1016/S1569-9056(17) 30292-0
19. Higgins JPT, Thomas J, Chandler J, et al. Cochrane Handbook for Systematic Reviews of Interventions. John Wiley \& Sons; 2019.

20. Moher D, Liberati A, Tetzlaff J, et al. Preferred reporting items for systematic reviews and meta-analyses: the PRISMA statement. PLoS Med. 2009;6(7):e1000097. doi:10.1371/journal.pmed.1000097

21. Shah D, Patil A, Reddy N, et al. A clinical experience of thulium fibre laser in miniperc to dust with suction: a new horizon. World J Urol. 2020. doi:10.1007/s00345-020-03458-8

22. Enikeev D, Glybochko P, Rapoport L, et al. A randomized trial comparing the learning curve of 3 endoscopic enucleation techniques (HoLEP, ThuFLEP, and MEP) for BPH using mentoring approachinitial results. Urology. 2018;121:51-57. doi:10.1016/j. urology.2018.06.045

23. Enikeev D, Glybochko P, Rapoport L, et al. Impact of endoscopic enucleation of the prostate with thulium fiber laser on the erectile function. BMC Urol. 2018;18(1). doi:10.1186/s12894-018-0400-1.

24. Enikeev D, Taratkin M, Klimov R, et al. Thulium-fiber laser for lithotripsy: first clinical experience in percutaneous nephrolithotomy.. World J Urol. 2020;38(12):3069-3074. doi:10.1007/s00345-020-03134-x

25. Enikeev D, Taratkin M, Klimov R, et al. Superpulsed thulium fiber laser for stone dusting: in search of a perfect ablation regimen-A prospective single-center study. J Endourol. 2020;34 (11):1175-1179. doi:10.1089/end.2020.0519

26. Enikeev D, Grigoryan V, Fokin I, et al. Endoscopic lithotripsy with a SuperPulsed thulium-fiber laser for ureteral stones: a single-center experience. Int J Urol. 2020.

27. Kuntz RM, Lehrich K, Ahyai SA. Holmium laser enucleation of the prostate versus open prostatectomy for prostates greater than 100 grams: 5-year follow-up results of a randomised clinical trial. Eur Urol. 2008;53(1):160-168. doi:10.1016/j.eururo.2007.08.036

28. Brunckhorst O, Ahmed K, Nehikhare O, et al. Evaluation of the learning curve for holmium laser enucleation of the prostate using multiple outcome measures. Urology. 2015;86(4):824-829. doi:10.1016/j.urology.2015.07.021

29. Enikeev D, Okhunov Z, Rapoport L, et al. Novel thulium fiber laser for enucleation of prostate: a retrospective comparison with open simple prostatectomy. J Endourol. 2019;33(1):16-21. doi:10.1089/ end.2018.0791

30. Lughezzani G, Jeldres C, Isbarn H, et al. Nephroureterectomy and segmental ureterectomy in the treatment of invasive upper tract urothelial carcinoma: a population-based study of 2299 patients. Eur J Cancer. 2009;45(18):3291-3297. doi:10.1016/j. ejca.2009.06.016

31. Favaretto RL, Shariat SF, Savage C, et al. Combining imaging and ureteroscopy variables in a preoperative multivariable model for prediction of muscle-invasive and non-organ confined disease in patients with upper tract urothelial carcinoma. BJU Int. 2012;109 (1):77-82. doi:10.1111/j.1464-410X.2011.10288.x

32. Chromecki TF, Cha EK, Fajkovic H, et al. The impact of tumor multifocality on outcomes in patients treated with radical nephroureterectomy. Eur Urol. 2012;61(2):245-253. doi:10.1016/j. eururo.2011.09.017

33. Cutress ML, Stewart GD, Tudor ECG, et al. Endoscopic versus laparoscopic management of noninvasive upper tract urothelial carcinoma: 20-year single center experience. $J$ Urol. 2013;189 (6):2054-2061. doi:10.1016/j.juro.2012.12.006

34. Villa L, Haddad M, Capitanio U, et al. Which patients with upper tract urothelial carcinoma can be safely treated with flexible ureteroscopy with holmium: YAG laser photoablation? Long-term results from a high volume institution. $J$ Urol. 2018;199(1):66-73. doi:10.1016/j.juro.2017.07.088

35. Musi G, Mistretta FA, Marenghi C, et al. Thulium laser treatment of upper urinary tract carcinoma: a multi-institutional analysis of surgical and oncological outcomes. J Endourol. 2018;32(3):257-263. doi:10.1089/end.2017.0915 
36. Wen J, Ji ZG, Li HZ. Treatment of upper tract urothelial carcinoma with ureteroscopy and thulium laser: a retrospective single center study. BMC Cancer. 2018;18(1):1-4. doi:10.1186/s12885-018-4118-y

37. Akand M, Muilwijk T, Raskin Y, et al. Quality control indicators for transurethral resection of non-muscle-invasive bladder cancer. Clin Genitourin Cancer. 2019;17(4):e784-e792. doi:10.1016/j. clgc.2019.04.014

38. Babjuk M, Böhle A, Burger M, et al. EAU guidelines on nonmuscle-invasive urothelial carcinoma of the bladder: update 2016. Eur Urol. 2017;71(3):447-461. doi:10.1016/j.eururo.2016.05.041

39. Hashem A, Mosbah A, El-Tabey NA, et al. Holmium laser en-bloc resection versus conventional transurethral resection of bladder tumors for treatment of non-muscle-invasive bladder cancer: a Randomized Clinical Trial. Eur Urol Focus. 2020. doi:10.1016/j. euf.2020.12.003

40. Enikeev D, Taratkin M, Margulis V, et al. Safety and short-term oncological outcomes of thulium fiber laser en bloc resection of non-muscle-invasive bladder cancer: a prospective non-randomized Phase II Trial. Bl Cancer. 2020;1-10.

41. Kronenberg P, Traxer O. The laser of the future: reality and expectations about the new thulium fiber laser-a systematic review. Transl Androl Urol. 2019;8(S4):S398-S417. doi:10.21037/tau.2019.08.01

42. Hardy LA, Irby PB, Fried NM. Scanning electron microscopy of real and artificial kidney stones before and after Thulium fiber laser ablation in air and water. In: Therapeutics and Diagnostics in Urology 2018. Vol. 10468. International Society for Optics and Photonics; 2018:104680G. doi:10.1117/12.2285069

43. Chan KF, Vassar GJ, Pfefer TJ, et al. Holmium: YAG laser lithotripsy: a dominant photothermal ablative mechanism with chemical decomposition of urinary calculi. Lasers Surg Med. 1999;25 (1):22-37.
44. Gross A, Becker B, Taratkin M, et al. MP24-10 Wavelength and pulse shape effects on stone fragmentation of laser lithotripters. J Urol. 2018;199(4S):e293-e294. doi:10.1016/j.juro.2018.02.763

45. Somani BK, Robertson A, Kata SG. Decreasing the cost of flexible ureterorenoscopic procedures. Urology. 2011;78(3):528-530. doi:10.1016/j.urology.2010.12.073

46. Chapman RA, Somani BK, Robertson A, et al. Decreasing cost of flexible ureterorenoscopy: single-use laser fiber cost analysis. Urology. 2014;83(5):1003-1005. doi:10.1016/j.urology.2013.12.019

47. Geraghty RM, Jones P, Herrmann TRW, et al. Ureteroscopy is more cost effective than shock wave lithotripsy for stone treatment: systematic review and meta-analysis. World $J$ Urol. 2018;36 (11):1783-1793. doi:10.1007/s00345-018-2320-9

48. New F, Somani BK. A complete world literature review of quality of life (QOL) in patients with kidney stone disease (KSD). Curr Urol Rep. 2016;17(12):1-6. doi:10.1007/s11934-016-0647-6

49. Jones P, Rai BP, Nair R, et al. Current status of prostate artery embolization for lower urinary tract symptoms: review of world literature. Urology. 2015;86(4):676-681. doi:10.1016/j.urology.2015.05.011

50. Jones P, Alzweri L, Rai BP, et al. Holmium laser enucleation versus simple prostatectomy for treating large prostates: results of a systematic review and meta-analysis. Arab J Urol. 2016;14 (1):50-58. doi:10.1016/j.aju.2015.10.001
Research and Reports in Urology

\section{Publish your work in this journal}

Research and Reports in Urology is an international, peer-reviewed, open access journal publishing original research, reports, editorials, reviews and commentaries on all aspects of adult and pediatric urology in the clinic and laboratory including the following topics: Pathology, pathophysiology of urological disease; Investigation and
Dovepress

treatment of urological disease; Pharmacology of drugs used for the treatment of urological disease. The manuscript management system is completely online and includes a very quick and fair peer-review system, which is all easy to use. Visit http://www.dovepress.com/ testimonials.php to read real quotes from published authors. 